\title{
Sistema econômico, direitos sociais e escolas desiguais: reflexões sobre a reforma do ensino médio
}

\author{
Economic system, social rights, and heterogeneous schools: \\ reflections on reform of high school \\ Sistema económico, derechos sociales y escuelas desiguales: reflexiones \\ sobre la reforma de la enseñanza secundaria \\ ANA LARA CASAGRANDE \\ KATIA MOROSOV ALONSO
}

Resumo: Neste artigo, cujo procedimento metodológico é a pesquisa bibliográfica, objetiva-se pensar a atual reforma do Ensino Médio, em um contexto capitalista. Faz-se uma recuperação histórica, a fim de mostrar que a educação transcorreu dualmente. Considera-se que a reconfiguração da etapa final da educação básica não rompe com a lógica do privilégio (currículos direcionados para a continuidade nos estudos no setor privado). Nota-se que a escola pública continua na contradição de: reproduzir os ideais dominantes, favorecendo o mercado; ser o espaço da crítica, articulação e socialização política.

Palavras-chave: Educação; Política educacional; Ensino Médio; Estado; Estratificação social.

Abstract: In this article, which methodological procedure is the bibliographical research, the objective is to think about the current reform of High School in a capitalist context. A historical recovery is made to show that education has evolved dually. It's considered that the reconfiguration of the end-stage of basic education does not break with the logic of privilege (curricula aimed at continuing the studies in the private sector). It's noted that the public school continues in the contradiction of reproducing the dominant ideals, favoring the market; and be the space of criticism, articulation and political socialization.

Keywords: Education; Educational administration; High school; State; Social class.

Resumen: En este artículo, cuyo procedimiento metodológico es la investigación bibliográfica, tiene por objetivo pensar la actual reforma de la Enseñanza Secundaria, en un contexto capitalista. Se hace una recuperación histórica, a fin de mostrar que la educación transcurrió dualmente. Se considera que la reconfiguración de la etapa final de la educación básica no rompe con la lógica del privilegio (currículos direccionados a la continuidad en los estudios en el sector privado). Se nota que la escuela pública sigue en la contradicción de: reproducir los ideales dominantes, favoreciendo el mercado; ser el espacio de la crítica, articulación y socialización política.

Palabras clave: Educación; Política educativa; Enseñanza Secundaria; Estado; Estratificación social. 


\section{INTRODUÇÃO}

A estrutura da educação, não apenas, mas também no Brasil, sempre esteve subordinada à desigualdade social, interessante para as elites, pois a concentração de poder se dá também pelo acesso ao conhecimento. Esse não é um embate superado para quem defende o estado de direito, isto é, aquele que deve garantir direitos sociais (sobretudo saúde e educação) a todos. Não se está referindo, no caso da educação, apenas ao acesso, há uma questão de qualidade, o termo é utilizado em contraposição à educação medíocre, aquela que tira dos "jovens talentosos a chance de adquirir as habilidades de que precisam para desenvolver e aplicar sua capacidade" (BAUMAN, 2015, p.27).

Neste texto, propõe-se um olhar crítico sobre a instituição escolar, especificamente quanto ao Ensino Médio, apontando limites e possibilidades para a proposição de mudanças na sua configuração, por meio do recurso metodológico: pesquisa bibliográfica, realizada "a partir do registro disponível, decorrente de pesquisas anteriores” (SEVERINO, 2007, p.122).

Falar dos limites é reconhecer o contexto com o qual se lida. Anunciar que há possibilidades é entender que há esperança, não enquanto palavra bela e vazia, mas traduzida em ação crítica, comprometida com seu propósito de resistência ao estabelecido e apoiada em uma práxis, no mesmo sentido da resistência ativa defendida por Saviani (2018), que implica a necessidade de ser coletiva e propositiva.

\section{EDUCAÇÃO E ESCOLA (BREVEMENTE) PROBLEMATIZADAS AO LONGO DOS SÉCULOS}

O Mediterrâneo antigo foi núcleo constitutivo do mundo ocidental, por isso, observam-se fatores ligados à educação, que mostram a dualidade existente desde o mundo antigo.

Considerando a educação no antigo Egito, Manacorda (2004, p.38) descreve a desigualdade educacional entre a casta dos sacerdotes e a massa popular. Aos primeiros, estava reservada "uma educação de casta dos sacerdotes, que é transmitida também de pai para filho e que consiste nas "letras sagradas' (ierà grámmata)", o autor esclarece que à juventude das classes dominantes cabia a tarefa da guerra e aos velhos a tarefa do culto e da cultura. Já, a massa popular era dividida entre os que exercem uma atividade ou arte, aquele que "aprende dos pais e dos parentes, desde a idade infantil, os ofícios que exercerá na sua vida", dado que se dedica a um ofício, aprende "a ler e escrever um pouquinho" (p.39); e aqueles que "não têm arte e nem parte - como se costuma dizer -, para 
os quais obviamente não há nenhuma transmissão educativa, nem de técnicas propriamente culturais" (MANACORDA, 2004, p.39). É possível observar, então, uma divisão entre instrução, formação para a arte da palavra; e trabalho, além dos excluídos de ambas.

$\mathrm{Na}$ Grécia, havia um processo de educação, voltado para o preparo das tarefas do poder (a política) na escola e outro, destinado ao fazer, às atividades laborais, um treinamento para o trabalho, inicialmente fora da escola, e nenhum projeto específico para as classes excluídas e oprimidas, "nenhuma escola e nenhum treinamento, mas em modo e em graus diferentes, a mesma aculturação que descende do alto para as classes subalternas" (MANACORDA, 2004, p.41). É interessante a observação que Manacorda (2004) faz a respeito da distinção entre dominantes e dominados: "passada em seguida para a nossa cultura, tem sua origem na escola pitagórica. Arquitas de Taranto escreve: 'Toda sociedade é formada de dominante e dominado: por isto, como terceiro elemento intervém a lei' (ibid., p.41). Nota-se a manutenção da discriminação do acesso ao saber e tipos de saberes.

A educação romana foi influenciada em grande medida pela grega, no entanto, não há a figura de um educador estrangeiro ou banido de sua pátria como na história grega, a exemplo de Fênix ou Pátroclo de Homero; a figura educadora central é a do pai, isto é, é forte a característica de uma educação que se dá essencialmente no seio da família. Manacorda (2004) faz uma observação importante quanto a essa característica exaltada pelos escritores romanos, de cujo relato se reconstrói a história da educação romana: "os testemunhos históricos referem-se sempre às classes dominantes, ignorando quase totalmente as classes produtoras e subalternas" (MANACORDA, 2004, p.74).

Cambi (1999, p.51), ao traçar a História da educação, destaca a polaridade educacional em duas das sociedades descritas: "A educação no mundo antigo, pré-grego e greco-romano é também uma educação por classes: diferenciadas por papéis e funções sociais, por grupos sociais e a tradição de que se nutre".

A Idade Média pode ser descrita como um período de grande influência da igreja na educação. Considerando o sistema dual educacional ao longo das sociedades, Manacorda (2004, p.357) relata o acirramento dessa cisão:

Às antigas divisões horizontais classistas entre quem se educa para 'o dizer e o fazer as coisas da cidade', acrescenta-se a divisão vertical entre os legales domini e os barbari reges, isto é, entre os homens de pena e os homens de espada, pertencentes inicialmente ao vencidos romanos, os outros aos vencedores bárbaros. Nisto a cultura (doctrina) adquire nova autonomia e prestígio, sem, todavia, democratizarse: desce do alto sob o povo cristão. 
Estado e igreja se imbricam no âmbito educacional, sobretudo fica visível tal relação nos altos graus do saber, nas universidades e nas escolas secundárias, hoje, o que chamamos de escolas de Ensino Médio. É possível observar a atuação forte dessas instituições nas escolas católicas até hoje, pois boa parte delas são colégios tradicionais.

No extremo Oriente, também é possível notar, talvez até mais marcadamente, uma educação dessemelhante, devido ao papel forte que as religiões desempenham para a conformação social (CAMBI, 1999). Na China, a religião confuciana favoreceu a separação entre governantes e governados, dando aos funcionários do estado, os chamados mandarins, escolas especializadas e intelectualizadas. Assim, a estrutura social permanece tradicional, como a educação: "dividida em classes, opondo cultura e trabalho, organizada em escolas fechadas e separadas para a classe dirigente (para as quais se compilam livros e se estudam técnicas de aprendizagem)" (ibid., p.63). O mesmo acontece na Índia "dominada pelas castas incomunicantes e imutáveis e pela religião védica, ligada à Brama e aos rituais secretos dos brâmanes" (ibid., p.63). Imobilismo e tradicionalismo também são observados no Japão: "organizada em rígidas classes sociais e por profissões, ligada a uma religião naturalista que valoriza a submissão à natureza e à ordem social" (ibid., p.63).

Ao utilizar-se do conceito de poder simbólico, Bourdieu (2001) esclarece que só pode ser exercido com a cumplicidade daqueles que estão sujeitos a ele. Os sistemas simbólicos exercem um poder estruturante (conhecer o mundo), na medida em que são também estruturados e tal estruturação decorre da função que os sistemas simbólicos possuem de integração social para um determinado consenso. Assim, o que ocorre é uma relação de luta, principalmente, simbólica, em que as diferentes classes estão envolvidas para imporem a definição do mundo social, conforme seus interesses (BOURDIEU, 2001).

Xavier (1994), mencionando especificamente a atuação dos religiosos católicos no campo educacional, afirma que havia projetos educativos diferenciados para as colônias, principalmente nas Américas espanhola e portuguesa, e para a Europa. No continente europeu, a Companhia de Jesus foi fundada para combater a Reforma Protestante, assim a sua atuação priorizou a educação das classes não populares, com a finalidade de combater o avanço do ideário protestante e do livre pensamento. As grandes massas populares deveriam ser conservadas na ignorância para perpetuar as posições sociais existentes. Enquanto no mundo colonial, a mesma Companhia atuava de formas distintas: para as classes dirigentes estava reservada a instrução para se formar a denominada elite intelectual e perpetuar a sua dominação sobre o povo colonizado; para as populações indígenas, catequese. Vale lembrar que, nos primeiros cinquenta anos da colonização brasileira, não 
havia escolas no Brasil, os jesuítas a inauguram com a missão de manter o trabalho braçal como "tarefa que Deus havia reservado a uma parcela da população que, expiando assim os seus pecados, teria o reino dos céus garantido" (XAVIER, 1994, p.47).

De modo geral, pode-se afirmar que a educação antitécnica sempre esteve reservada para as elites, para que realizassem o trabalho intelectual, ligado à vida política: "Todo o mundo antigo até a revolução cultural do cristianismo, permanecerá ancorado a esse dualismo radical de modelos formativos, que refletem e se inserem naquele dualismo entre trabalho manual e trabalho intelectual" (CAMBI, 1999, p.51-52).

Com o decorrer do tempo, a burguesia vai mudando a configuração político-econômica, sem que se alterasse o cenário de uma educação direcionada aos burgueses e outra, às classes desfavorecidas. A escola também se adapta, ao mesmo tempo em que há lutas "pela estatização, democratização e laicização da instrução [...] verifica-se 'a aliança do saber com a indústria" (MANACORDA, 2004, p.359).

O que se observa por meio dessa contextualização histórica vai ao encontro da constatação já realizada por Saviani (2016, p.41), de que "desvela-se a impossibilidade da sociedade capitalista realizar as expectativas que ela própria proclama. Evidencia-se, assim, a im $\neg$ possibilidade da universalização efetiva da escola; a impossibilidade do acesso de todos ao saber".

Soma-se à educação dividida em classes, um elemento de gênero importante para a história da educação brasileira. Saviani et al (2014), tratando da figura feminina na educação, lembra que em meados de 1920 as mulheres precisavam de autorização de um homem (o pai ou marido) para estudar. Por volta de 1942, as classes eram separadas nas escolas. Para os homens estava reservada uma educação voltada para a introdução ao mundo político e às mulheres, o desenvolvimento do papel materno. É com esse enviesamento da maternidade que as mulheres podem inserir-se no magistério, diante da expansão das escolas públicas, já na década de 1960 .

No final do século XX, os movimentos feministas desenvolvem um importante papel no questionamento da subordinação feminina e as mulheres expandem a sua atuação para os mais diversos cargos dentro das escolas. Não que isso signifique, ainda, igualdade com os homens, em termos de cargos em que atuam predominantemente e valores salariais (SAVIANI et al, 2014). Um exemplo de tímida ocupação dos espaços educacionais, fora do âmbito do magistério (ligado ao cuidado/ instinto materno), é o estudo "Acesso da Mulher ao Ensino 
Superior Brasileiro" (BARROSO e MELLO, 1975), cujos resultados mostraram que, em 1971, a porcentagem de mulheres matriculadas em cursos de Engenharia era de $3 \%$.

\section{EDUCAÇÃO BRASILEIRA E A NOÇÃO MERCADOLÓGICA}

Quando o Brasil se torna independente de Portugal, o fato se dá por um cumprimento formal, dado que a realidade social, política e econômica brasileira não apresentou profundas modificações para a população. Segundo Xavier (1994, p.62), a independência "se constituiu, de fato, num arranjo político que favorecia os interesses da camada senhorial brasileira, grande empresária da emancipação política, assim como os interesses do novo capitalismo europeu".

O novo capitalismo era uma realidade impossível de ser negada e a educação tem posição central no projeto de reestruturação do capital nas políticas internacionais. No Brasil, o alinhamento com tais orientações políticas dá-se com maior ênfase a partir dos anos de 1990, aparecendo materializada no Plano Diretor da Reforma do Aparelho do Estado (PDRAE), elaborado no primeiro mandato do Governo Fernando Henrique Cardoso (1995-1998), pelo Ministério da Administração Federal e da Reforma do Estado (MARE), cujo ministro era Luiz Carlos Bresser-Pereira.

O PDRAE propunha a reforma do Estado brasileiro, que correspondia a limitar as funções do Estado como produtor de bens e serviços e, em menor extensão, como regulador (PEREIRA, 2006); na prática, para Peroni (2003), acabou por promover um afastamento do Estado das responsabilidades relativas às questões sociais.

O Estado, na concepção do PDRAE, tendeu a assumir funções diretas de execução, ineficientes, que deixaram claro que reformar o Estado significa transferir para o setor privado as atividades que poderiam ser controladas pelo mercado (BRASIL, 1995). Nesse sentido, o mercado é a referência de qualidade e se constrói um "fetichismo da mer $\neg$ cadoria" (SAVIANI, 2016, p.41).

A escola de Período Integral (EPI), instituída em algumas escolas do estado de São Paulo, traz uma lógica empresarial para a educação pública, à medida que insere a contratação por designação, segundo a qual os professores que atuam na escola podem ser reencaminhados (dispensados do projeto) para outra escola, se forem efetivos da rede $^{1}$ (CASAGRANDE e ADAM, 2017).

\footnotetext{
1 Os professores efetivos voltam para a escola na qual possuem sede. Lembrando que ninguém tem sede na Escola de Período Integral. Se pertencerem à categoria sem estabilidade (categoria O), os professores voltam a pleitear aulas disponíveis para atribuição na rede. A dispensa implica em perda do adicional salarial e da dedicação exclusiva, próprios da EPI.
} 
A reinauguração do ensino técnico integrado ao Ensino Médio e sua flexibilização curricular, obrigatória para a rede pública de ensino, no que o Ministério da Educação chama de "Novo Ensino Médio" é um indício da política educacional, explicitando a educação destinada ao jovem pobre. Com a flexibilização da grade curricular, o novo modelo traz a proposta de uma parte que será comum e obrigatória a todas as escolas (Base Nacional Comum Curricular) e outra parte flexível. Uma teoria pedagógica com proposta similar é a pedagogia tecnicista, que não é nova e, como Saviani (2012, p.13) já enunciou há décadas, nessa perspectiva, a educação contribuiria

[...] para superar o problema da marginalidade na medida em que formar indivíduos eficientes, portanto, capazes de darem sua parcela de contribuição para o aumento da produtividade da sociedade. Assim, estará ela cumprindo sua função de equalização social. Nesse contexto teórico, equalização social é identificada com o equilíbrio do sistema (no sentido do enfoque sistêmico). A marginalidade, isto é, a ineficiência e improdutividade se constitui numa ameaça à estabilidade do sistema. Como este comporta múltiplas funções, às quais correspondem determinadas ocupações, [...] cabe à educação proporcionar um eficiente treinamento para a execução das múltiplas tarefas demandadas continuamente pelo sistema social.

O mercado descobriu a educação como uma possibilidade altamente lucrativa, quando passou a expandir e diversificar suas áreas de interesse: gestão escolar, material pedagógico, currículo, avaliação, vagas, dentre outros.

Constatando-se que, em certa medida, a política educacional tem legitimado a noção de educação como mercadoria, cujo cliente estabelece relação individual direta com a concorrência, cabe a reflexão sobre o campo jurídico, trazida por Bourdieu (2001), no qual a política se torna espaço de concorrência pelo monopólio do direito de dizer o direito, ou seja, de interpretar textos que consagram a visão legítima do mundo social. Assim, a disputa pelos meios jurídicos favorece um trabalho contínuo de racionalização, de modo a parecer que impõem as normas jurídicas, totalmente independentes, das relações de força que ele sanciona e consagra.

Dessa forma, estende-se o espaço judicial ao qual o autor se refere para o espaço da política pública, que implica a imposição de uma fronteira entre os que estão preparados para entrar no jogo, conhecem as regras e possibilidades de atuação e os que, quando nele se acham lançados, permanecem, de fato, excluídos por não poderem operar uma conversão de um espaço mental (linguístico, em particular, mas relativo a outros âmbitos também). 
A constituição de um saber científico leva à desqualificação do sentido de equidade dos não especialistas (BOURDIEU, 2001). Por isso, acredita-se ser uma ação de resistência (necessária), por parte da escola, cuidar da socialização política, com os termos, com o funcionamento, operacionalização... para que as massas estejam aptas a participar dos espaços legitimados de tomada de decisão.

\section{MUNDIALIZAÇÃO, MERCANTILIZAÇÃO E ALTERAÇÕES NAS POLÍTICAS EDUCACIONAIS}

A tendência mundial de menor intervenção estatal envolve a privatização de bens e serviços que cabiam ao Estado e eram considerados como, apenas, públicos. Concorda-se com Montaño (2008) que a proposta de privatizar bens públicos ratifica uma estratégia de reestruturação do capital. Montaño (2008, p.216) afirma que, "na verdade, o fundamento da crise fiscal do Estado tem mais a ver com o uso político e econômico que as autoridades, representantes de classe, têm historicamente feito em favor do capital" (grifos do autor), dessa maneira, o estabelecimento de um setor privado com interesse público também operaria nesse sentido para o autor.

Visto que para a teoria Neoliberal, não é o sistema do capital e sua possibilidade de aumento do lucro que está em crise, mas o Estado, a privatização é uma estratégia de "retirada do Estado das políticas sociais universais" (PERONI, OLIVEIRA e FERNANDES, 2009, p. 764). Seguindo as proposições de Peroni (2003), vemos que os teóricos neoliberais não são os únicos adeptos da concepção de que se trata de uma crise do Estado, os propositores da Terceira Via também partem da premissa de que a crise se manifesta no Estado e não no sistema do capital. Os métodos propostos pela Terceira Via para a solução da crise são diferentes, mas também há orientações de estabelecimento de parcerias entre o público e o privado. Peroni, Oliveira e Fernandes (2009, p.764/765) afirmam que ao propor a parceria público-privada, chamados também de convênios, a Terceira Via "reduz o papel do Estado na execução das políticas sociais, repassando principalmente para o público não-estatal ou terceiro setor, e o que permanece sob a esfera estatal passa a ter a lógica de mercado".

O neoliberalismo e a terceira via são correntes teóricas distintas, mas ambas "engendraram novas reconfigurações entre público e privado, tecendo outras relações no campo das políticas sociais, de forma geral, e da política educacional, particularmente" (PERONI, OLIVEIRA e FERNANDES, 2009, p. 774). 
Para os teóricos, adeptos do neoliberalismo, o qual Peroni (2003) define como ideologia própria da nova fase do capitalismo, o que se deu não foi uma crise do capital como postulam outras teorias; a crise era do estado de bem-estar social e, como coloca Anderson (1995), esses teóricos acreditavam, ainda, que as raízes da crise econômica de 1973 se encontravam no poder exercido pelos sindicatos e operários, cujas pressões reivindicativas de direitos trabalhistas aumentavam os gastos sociais.

Em perspectiva contrária aos teóricos neoliberais, Harvey (2004, p.77) acredita que são próprias da acumulação do capital as "contradições internas, tendentes a gerar crises". Seu argumento se relaciona a uma tendência do capitalismo, a que chama de crônica, em "produzir crises de sobreacumulação [...] tipicamente registradas como excedentes de capital (em termos de mercadoria, moeda e capacidade produtiva) e excedentes de força de trabalho" e deriva "teoricamente de uma reformulação da teoria da tendência da queda da taxa de lucro, de Marx" (HARVEY, 2004, p.78).

Assim, Harvey (1992, p.124) diz que, diante de um grande momento de estagnação do lucro do capital dado pelo colapso econômico do período pós Segunda Guerra Mundial (1939-1945), o estado capitalista assumiu novas obrigações, procurando "chegar a arranjos políticos, institucionais e sociais que pudessem acomodar a crônica incapacidade do capitalismo de regulamentar as condições essenciais de sua própria reprodução".

Em resposta à falta de oportunidade de lucro do capital, sempre ameaçadora para esse sistema (HARVEY, 2004), surgiu uma nova conjuntura que, em síntese, "se põe como uma alternativa teórica, econômica, ideológica, éticopolítica e educativa à crise do capitalismo deste final de século" (FRIGOTTO, 1995, p.79).

Também nos anos 1990, no Brasil, o Banco Mundial assume papel decisivo nas políticas educacionais implementadas - desenvolve um documento para o Brasil, especificamente, como faz para cada país que tome seus empréstimos (PERONI, 2003) - com posição explícita, afirma Miranda (1996 apud PERONI, 2003, p.97), “da vinculação entre educação e produtividade, uma visão claramente economicista, sem preocupação de vinculação desses objetivos ao desenvolvimento da cidadania".

As orientações vêm no sentido de aproximar a ideia de escola a das empresas, o que Ball (1995, p. 199-200) critica, dizendo que existe uma tendência, principalmente por parte dos políticos, a falar nos mercados "apenas em termos de efeitos e resultados positivos: eles imaginam uma utopia de mercado, na qual todas as escolas se tornarão melhores e a mágica da competição assegura que todo 
consumidor seja feliz". Devido à aproximação da lógica das escolas com a das empresas, segundo Saviani (2005), a educação passa a ser concebida como dotada de um valor econômico próprio e considerada um bem de produção (capital).

Desse modo, nota-se a incorporação da "noção da alternativa de mercado na educação" (BALL, 1995, p.196), na qual a educação é vista como mais um espaço propício para o lucro do capital.

\section{ESCOLA PÚBLICA, REFORMA DO ENSINO MÉDIO E A NOVA CONJUNTURA PARA EDUCAÇÃO DO JOVEM NO BRASIL}

Diante dos problemas apresentados, inclusive desde o Mundo Antigo, há uma tendência de que o pessimismo tome conta e não enxerguemos a escola como um espaço a partir do qual seja possível emergir algo mais do que a reprodução do favorecimento dos já privilegiados ou de retradução das desigualdades. No entanto, a provocação para o ânimo vem do questionamento: se não a escola, por qual outra instituição passará a transformação em termos sociais?

Consegue-se dimensionar as possibilidades da escola, quando há um projeto chamado "Escola sem partido", que quer calar a voz da crítica, da dissonância, que está presente na instituição escolar (ou em algumas delas). A escola é o lugar da crítica, entendendo lugar na acepção de Cunha (2010, p. 5354):

O lugar se constitui quando atribuímos sentido aos espaços, ou seja, reconhecemos a sua legitimidade para localizar ações expectativas, esperanças e possibilidades. Quando se diz que "é o lugar de" extrapolamos a condição de espaço e atribuímos um sentido cultural, subjetivo e muito próprio ao exercício de tal localização. Minha gaveta pessoal de pertences é um espaço, mas quando coloco minhas coisas dentro dela e reconheço a propriedade dessa organização, defino um lugar. (grifo da autora)

Quando um professor de História questiona o relato histórico difundido de que o Brasil foi "descoberto" em 1.500, retomando a reflexão de que havia um povo no país antes da chegada dos portugueses, corresponderia a partidarismo? Ou o seria quando o profissional retoma a História de um país com base no livro didático escrito na perspectiva europeia? A ironia é necessária, pois fica claro que o projeto é uma afronta à liberdade de aprender e ensinar, preconizadas pela própria legislação brasileira (Constituição Federal de 1988 e LDB) e coloca em cheque a competência profissional do docente e crítica do aluno. Mas, falar em regular a ação pedagógica dentro da escola faz pensar inevitavelmente em suas 
coisas: há potencial de engajamento e atuação nessa juventude que está na escola; com o conhecimento e poder de alcance que têm, os professores são potenciais articuladores de movimentos em prol de uma mudança.

Não seria possível descrever especificamente que tipo de mudança temem os propositores de uma suposta escola, supostamente neutra, mas apenas a que se pretende nos limites deste texto: que os privilégios não existam no escopo da igualdade de direitos, que a ideologia dominante (cuja função é ocultar as diferenças sociais e políticas, fazendo-as parecerem naturais [CHAUÍ, 2000]) não seja mais o texto da lei e o lucro, a regra maior a qual estão submetidos todos, inclusive a maioria que dele não goza. Diz-se maioria, considerando que "a riqueza combinada das cem pessoas mais ricas do mundo é quase duas vezes maior que aquela dos 2,5 bilhões de mais pobres" (BAUMAN, 2015, p.16). Que se alterem os rumos da "democratização tardia, criada e cevada para servir à elite", como Mendonça (2001, p.84) denuncia.

Um caminho profícuo seria o estímulo à colaboração nas ações dentro do espaço escolar. Há uma forte ideologia para que os professores e escolas compitam entre si em um jogo irracional, em que se leva a questionar: o que um(a) professor(a)/escola ganha quando o outro(a) perde?

Profissionalizar os trabalhadores em educação parece necessário, para isso, seria importante repensar o espaço da universidade, o lugar de formação inicial de professores, mas cujo prestígio está na pesquisa, fazendo com que essa formação tão importante fique em segundo plano.

O fortalecimento da gestão democrática nas escolas públicas é uma forma de trazer identificação com o projeto da instituição e chamar a Comunidade Escolar a interessar-se pelo processo ensino-aprendizagem para o coletivo. A escola pública não é do(a) direitor(a) ou de qualquer outra pessoa, especificamente. Um dos elementos responsáveis por tal crença é a característica patrimonial do Estado brasileiro, não puramente burocrático, mas que se configurou em um híbrido de burocracia patrimonial (MENDONÇA, 2001). Segundo Mendonça (2001, p.97):

É essa maneira autocrática e autoritária de funcionamento do Estado, característica do governo estamental, que permite que as políticas públicas, de que a gestão democrática do ensino público é apenas um exemplo, sejam constantemente alteradas, ao sabor das conveniências políticas. O governante dita à sociedade a sua vontade pessoal como se estatal fosse, numa versão adaptada e moderna do coronelismo, elemento que participa da estrutura patrimonial e que transforma o governante no dono do governo. 
Apenas por meio da participação é possível frear o processo de retrocesso do coronelismo. O processo de democratização brasileiro foi tardio e, hoje, está ameaçado.

Ao analisar a atual conjuntura do país, Saviani (2018, p.3) afirma que a crise política brasileira foi agravada com a deposição da presidenta eleita, o que ele considera "quebra da institucionalidade democrática". Assim, o autor fala na necessidade de restabelecê-la.

Aprovar uma importante alteração para a educação da juventude do país, via Medida Provisória, é um dos elementos que nos fazem questionar o lugar da política educacional no sistema democrático atual. Ao pensar na educação desses jovens, estamos nos referindo especificamente ao Ensino Médio.

A Reforma do Ensino Médio foi editada por Michel Temer (que assumiu a presidência da República após um controverso processo de impeachment de Dilma Rousseff) por meio de Emenda Constitucional, como dito, cuja origem está na Medida Provisória n 746, de 2016. A Medida Provisória é um recurso permitido pela Constituição Federal, caracterizado como um instrumento com força de lei, adotado pelo presidente da República, em casos de relevância e urgência. No caso do Ensino Médio, causa estranheza o fato de não dar-se "conhecimento prévio às Secretarias de Educação e aos Conselhos Estaduais de Educação que, pela Constituição e pela LDB, são os responsáveis pela oferta pública desse nível de ensino" (SAVIANI, 2018, p.7).

Desse modo, a Lei no 13.415, de 16 de fevereiro de 2017 institui a Política de Fomento à Implementação de Escolas de Ensino Médio em Tempo Integral. Essa lei, que pretende trazer o "Novo Ensino Médio" (BRASIL/MEC, 2017), estabelece que a carga horária mínima anual seja de oitocentas horas, distribuídas por um mínimo de duzentos dias de efetivo trabalho escolar, excluído o tempo reservado aos exames finais, quando houver (nova redação dada ao art. 24 da Lei de Diretrizes e Bases da Educação [LDB] - Lei no 9.394, de 20 de dezembro de 1996). Tal ampliação será feita de forma progressiva, no ensino médio, para mil e quatrocentas horas, devendo os sistemas de ensino oferecerem, no prazo máximo de cinco anos, pelo menos mil horas anuais de carga horária, a partir de 2 de março de 2017 (BRASIL, 2017, art. $1^{\circ}, \mathbb{\$} 1^{\circ}$ ).

Com tal ampliação da jornada, nota-se que uma das principais alterações diz respeito à instituição do tempo integral no Ensino Médio. Ao estudar a Lei de Diretrizes e Bases (LDB), Demo afirma que o Senador Darcy Ribeiro, propositor dessa lei no senado, "era o maior defensor nacional da escola de tempo integral" (DEMO, 2013, p.14). Apesar disso, o autor considera que na LDB, “a formulação é branda", mas mostra "o caminho futuro para a escola de tempo integral como algo que a sociedade irá naturalmente exigir” (ibid., p.13). 
No art. 34 da LDB, ao falar da jornada escolar, estabelece-se a ampliação progressiva do período de permanência na escola (BRASIL, 1996), ainda bastante voltado para o Ensino Fundamental na proposição da década de 1990, como se percebe no último capítulo (Das Disposições Transitórias), no qual se fala em conjugar "todos os esforços objetivando a progressão das redes escolares públicas urbanas de Ensino Fundamental para o regime de escolas de tempo integral" (BRASIL, 1996, art. 87, $\$ 5^{\circ}$ ).

No entanto, aquele caminho rumo à escola de tempo integral efetivamente foi percorrido, de maneira que, em boa parte das políticas públicas de educação, ela é proposta, inclusive com experiências práticas anteriores à Reforma que aqui se discute, a qual abrange todo o país. O Ensino Médio de tempo integral já se fazia presente em alguns estados, como Pernambuco, São Paulo e Mato Grosso.

Com relação aos conteúdos a serem ministrados, a atual proposta de expansão do ensino em tempo integral no Ensino Médio, afirma, em acréscimo ao artigo 35 da LDB (BRASIL, 1996): 35-A, que os conteúdos mínimos necessários para essa etapa serão definidos na Base Nacional Comum Curricular (BNCC), que estabelecerá direitos e objetivos de aprendizagem, conforme diretrizes do Conselho Nacional de Educação (BRASIL, 2017, art. $3^{\circ}$ ).

O currículo do Ensino Médio será composto, além da BNCC, por itinerários formativos, organizados por meio da oferta de diferentes arranjos curriculares, conforme a relevância para o contexto local e a possibilidade dos sistemas de ensino - essa diretriz dá nova redação ao art. 36 da LDB - (BRASIL, 2017, art. $4^{\circ}$ ). Os itinerários formativos dizem respeito à formação com ênfase técnica e profissional. No mesmo artigo (\$ 11 ), ainda, prevê-se a possibilidade, para efeito de cumprimento das exigências curriculares do ensino médio, de que os sistemas de ensino firmem convênios com instituições de educação a distância com notório reconhecimento; orientação aos alunos no processo de escolha das áreas de conhecimento ou de atuação profissional (\$ 12).

Ao promover uma análise sobre a estrutura do Ensino Médio, Ferretti (2015) considera que este não pode ser fatiado em especializações, uma vez que faz parte da formação básica do estudante. Já desde o ano de 2013, no art. $36\left(\right.$ ( $\left.5^{\circ}\right)$ do Projeto de Lei no 6840/2013, por exemplo, se determinava que a última série ou equivalente do Ensino Médio fosse organizada a partir de opções formativas. Para o autor, é uma retomada da chamada "Reforma Francisco Campos", empreendida no início da Era Vargas (1930-1945), sob o comando do ministro da educação Francisco Campos que, mesmo atendendo a diversas ideias, difundidas na época na área da educação, deu continuidade "apenas à formação das elites, uma vez que não alterou o sistema fechado do secundário" (SOARES, DASSIE e ROCHA, 2004, p.8). 
Cabe lembrar que a Reforma Francisco Campos foi imposta em âmbito nacional, na legislação, pelo fato de o país, naquele momento, viver em regime de exceção, logo após o desfecho do golpe de estado, chefiado por Getúlio Vargas.

No tocante aos professores que atuarão no Ensino Médio renovado de 2017, o art. $6^{\circ}$ da Lei n ${ }^{\circ} 13.415 / 2017$ estabelece que profissionais com notório saber, reconhecido pelos respectivos sistemas de ensino, possam ministrar conteúdos de áreas afins à sua formação ou experiência profissional, atestados por titulação específica ou prática de ensino em unidades educacionais da rede pública ou privada ou das corporações privadas em que tenham atuado. Além de profissionais graduados que tenham feito complementação pedagógica, conforme disposto pelo Conselho Nacional de Educação.

Com relação aos recursos financeiros, no art. 14 (BRASIL, 2017) são estabelecidas como obrigatórias as transferências anuais de recursos da União aos Estados e ao Distrito Federal, via valor único por aluno, às escolas públicas de Ensino Médio em tempo integral, cadastradas no Censo Escolar da Educação Básica que iniciaram a oferta de atendimento em tempo integral, a partir da vigência dessa Lei, com prioridade às regiões com menores índices de desenvolvimento humano e com resultados mais baixos nos processos nacionais de avaliação do ensino médio; e que tenham projeto político-pedagógico, obediente ao disposto no art. 36 da LDB.

A transferência dos recursos financeiros será realizada automaticamente pelo FNDE, dispensada a celebração de convênio, acordo, contrato ou instrumento congênere, mediante depósitos em conta corrente específica (BRASIL, 2017, art. 15).

Além da preocupação com o direcionamento dos jovens pobres para a escolha de itinerários formativos que limitem a sua continuidade nos estudos, o que não ocorre com o jovem abastado, para o qual a universidade é um caminho óbvio, alertamos para o estabelecimento de ampliação da jornada e oferecimento de cursos técnicos, atrelados à Educação Básica, que significa obviamente ampliação dos custos para seu provimento, em um contexto de promulgação da Emenda Constitucional 95, que limita por 20 (vinte) anos os gastos públicos, com origem na Proposta de Emenda Constitucional n 55 de 2016, que institui o novo regime fiscal.

Outro ponto de necessária reflexão diz respeito à ampliação do atendimento. A meta do PNE (2014-2024), Lei no 13.005, de 25 de junho de 2014, em vigência, é a de universalizar, ainda no ano de 2016, o atendimento escolar (engloba o porcentual da população em idade escolar que frequenta a escola) para toda a população de quinze a dezessete anos e elevar, até o final do seu período de vigência, a taxa líquida de matrículas (indica o porcentual da população em 
determinada faixa etária que se encontra matriculada no nível de ensino adequado à sua idade) no Ensino Médio para oitenta e cinco por cento (BRASIL, 2014). Mas, com a instituição da EPI se observou uma significativa transferência dos alunos trabalhadores para escolas de período parcial. Isto é, chamamos a atenção para o caráter seletivo da escola que acolhe jovens que podem ficar o dia todo no espaço escolar, o que não corresponde à realidade de muitos estudantes pobres do país.

\section{CONSIDERAÇÕES FINAIS}

Acredita-se que a escola seja a instituição pela qual passe a mudança pretendida para a sociedade atual, com relação às oportunidades de acesso à educação de qualidade (um direito social constitucional) e realização profissional. Apesar de não ser possível desconsiderar seus limites, considera-se, como Manacorda (2004, p.360) que “o fato educativo é um 'politikum' e um social, consequentemente, é também verdadeiro que toda situação política e social determina sensivelmente a educação". Portanto, não é possível defender uma educação diferente, desarticulada das ações políticas que estejam a tal favor dentro da escola.

Nota-se que a atual Reforma do Ensino Médio, instituída pela Lei ${ }^{\circ}$ 13.415/2017, não rompe com a lógica da política pública que favorece o grupo privilegiado, aquele relativo à juventude que tem acesso a currículos voltados para sua continuidade nos estudos. As escolas privadas também aderirão à BNCC e aos diferentes itinerários formativos? A pergunta é provocativa para mostrar que esses jovens têm um objetivo claro de ingressar na universidade. Ao passo que fazer com que os jovens pobres se especializem precocemente seja um modo de dizer qual é o seu lugar na sociedade, qual projeto de vida é possível no âmbito da educação pública.

Esse é o problema central, verificado aqui, ao qual se somam outros, como os profissionais com notório saber: falta uma definição clara de quem são os novos atores convidados a compor a equipe escolar; financiamento: causa preocupação que os fundos estabelecidos no que tange ao financiamento realmente sustentarem um projeto que carece de investimento, em um contexto de congelamento de investimento em serviços públicos (por 20 anos); possibilidade de o público alvo estudar em tempo integral: alerta-se para a seleção indireta dos alunos. Quando a estratégia abarca todo o país, não sabemos até que ponto o ensino noturno dará conta da nova demanda, associado ao risco de aumentaremse os índices de evasão no Ensino Médio, já tão alarmantes nessa etapa, como comprovam os dados do Censo Escolar. 
Além disso, observa-se que a escola pública continua na contradição de: reproduzir os ideais dominantes, fornecendo mão-de-obra para o mercado (por meio do currículo, por exemplo); ser o espaço da crítica, articulação e resistência das massas (socialização política). É uma contradição, pois ao mesmo tempo em que enxergamos os problemas da escola, ainda acreditamos em suas possibilidades, em uma sociedade estruturada na desigualdade socioeconômica. Nesse sentido, considera-se a escola, hoje, como lócus para um olhar atento sobre o futuro do jovem pobre brasileiro e sua possibilidade em dar continuidade aos estudos, diante das atuais perspectivas políticas.

Salienta-se a necessidade de se continuarem as reflexões sobre as possibilidades de atuação dentro do espaço escolar e a reverberação das necessidades sociais em termos de políticas públicas, com a finalidade de que levem em conta: o problema estrutural da educação dual, as políticas reformistas empreendidas, o teor ideológico das políticas educacionais, a mercantilização da educação, a supervalorização dos dados estatísticos nas avaliações, a responsabilização docente, a produção científica na perspectiva eurocentrada e o direcionamento do estudante pobre para a especialização precoce e entrada no mercado de trabalho, em nome de uma educação como expressão da efetivação do direito de todos ao conhecimento, de fato.

\section{REFERÊNCIAS}

BALL, S. J. Mercados educacionais, escolha e classe social: o mercado como uma estratégia de classe. In: GENTILI, P. (Org.). Pedagogia da exclusão: crítica ao neoliberalismo em educação. Petrópolis: Vozes, 1995. p.196-227.

BARroso, C. L. de M.; MELLO, G. N. de. O acesso da mulher ao ensino superior brasileiro. In: XXVII Sociedade Brasileira para o Progresso da Ciência SBPC. Comunicação. Anais do... Belo Horizonte, 1975.

BAUMAN, Z. A riqueza de poucos beneficia todos nós? Trad. Renato Aguiar. $1^{\mathrm{a}}$ ed. Rio de Janeiro: Zahar, 2015.

BOURDIEU, P. O poder simbólico. Trad. Fernando Tomaz. Rio de Janeiro: Bertrand Brasil, 2001.

BRASIL. Ministério da Administração e Reforma do Estado. Plano Diretor da Reforma do Aparelho do Estado. Brasília, DF: 1995. 
BRASIL. Lei no 9.394, de 20 de dezembro de 1996. Brasília, DF: 1996.

BRASIL. Plano Nacional de Educação. Lei no 13.005, de 25 de junho de 2014. Brasília, DF: 2014.

BRASIL. Lei $\mathbf{n}^{\circ}$ 13.415, de 16 de fevereiro de 2017. Brasília, DF: 2017.

BRASIL. MINISTÉRIO DA EDUCAÇÃO. Novo Ensino Médio - perguntas e respostas. Disponível em http://portal.mec.gov.br/component/content/ article?id=40361\#nem_05. Acesso em: 17 jun. 2019.

CAMBI, F. História da Pedagogia. Trad. Álvaro Lorencini. São Paulo: Fundação Editora da Unesp (FEU), 1999.

CASAGRANDE, A. L.; ADAM, J. M. Gestão pública da educação paulista: a carreira docente e o novo Ensino Médio. Curitiba: CRV, 2017.

CHAUÍ, M. Convite à filosofia. São Paulo: Ática, 2000.

CUNHA, M. I. da. Trajetórias elugares da formação da docência universitária: da perspectiva individual ao espaço institucional. Araraquara: Junqueira e Marin Editores, 2010.

DEMO, P. A nova LDB: ranços e avanços. 23ª ed. Campinas, Papirus, 2013.

FRIGOTTO, G. Os delírios da razão: Crise do capital e metamorfose conceitual no campo educacional. In: GENTILI, P. (Org.). Pedagogia da exclusão: crítica ao neoliberalismo em educação. Petrópolis: Vozes, 1995. p.77-108.

HARVEY, D. Condição pós-moderna. São Paulo: Edições Loyola, 1992.

HARVEY, D. O novo imperialismo. São Paulo: Edições Loyola, 2004.

MANACORDA, M. A. História da educação: da antiguidade aos nossos dias. Trad. Gaetano Lo Monaco. São Paulo: Cortez, 2004.

MENDONÇA, E. F. Estado Patrimonial e Gestão democrática do Ensino Público no Brasil. Educação \& Sociedade, n.75, ano XXII, ago. 2001. 
MONTAÑO, C. O terceiro setor e a questão social: crítica ao padrão emergente de intervenção social. $5^{a}$ ed. São Paulo: Cortez, 2008.

PEREIRA, L. C. B. Gestão do setor público: estratégia e estrutura para um novo Estado. In: PEREIRA, Luiz Carlos Bresser; SPINK, Peter (org.) Reforma do Estado e administração pública gerencial. Rio de Janeiro: Editora FGV, 2006. p.21-38.

PERONI, V. M. V. Política educacional e o papel do Estado: no Brasil dos anos 1990. São Paulo: Xamã, 2003.

PERONI, V. M. V.; OLIVEIRA, R. T. C. de; FERNANDES, M. D. E. Estado e terceiro setor: as novas regulações entre o público e o privado na gestão da educação brasileira. Educação \& Sociedade, vol.30, n.108, Campinas, out. 2009.

SAVIANI, D. Escola e Democracia. 42 ed. Campinas, SP: Autores Associados, 2012.

SAVIANI, D. Transformações do capitalismo, do mundo do trabalho e da educação. In: LOMBARDI, J. C. e SAVIANI, D. (Org.). Capitalismo, trabalho e educação. Campinas: Autores Associados, 2005. p. 13-24.

SAVIANI, D. et al. (Org.). O Legado Educacional do Século XX no Brasil. $3^{a}$ ed. Campinas: Autores Associados, 2014.

SAVIANI, D. A crise estrutural do capitalismo e seus impactos na educação pública brasileira. In: LOMBARDI, J. C. (org.) Crise capitalista e educação brasileira. Uberlândia, MG: Navegando Publicações, 2016. p.31-44.

SAVIANI, D. Crise do capitalismo, crise política no Brasil e retrocesso na educação. In: Cadernos de Análises da Conjuntura, n. 1, p.1-10, jan. 2018.

SEVERINO, J. Metodologia do trabalho científico. $23^{\mathrm{a}}$ ed. São Paulo: Cortez, 2007.

SOARES, F. dos S.; DASSIE, B. A.; ROCHA, J. L. Ensino de matemática no século XX - da Reforma Francisco Campos à Matemática Moderna. Horizontes, Bragança Paulista, v. 22, n. 1, p. 7-15, jan./jun. 2004. 
XAVIER, M. E. S. P. História da educação: a escola no Brasil. São Paulo: FTD, 1994.

ANA LARA CASAGRANDE é Professora Adjunta da Universidade Federal de Mato Grosso/campus Cuiabá, Departamento de Ensino e Organização Escolar - Instituto de Educação.

E-mail: analaracg@gmail.com

ORCID: https://orcid.org/0000-0002-6912-6424

KATIA MOROSOV ALONSO é Professora Associada da Universidade Federal de Mato Grosso/campus Cuiabá, Departamento de Ensino e Organização Escolar - Instituto de Educação.

E-mail: katia.ufmt@gmail.com

ORCID: https://orcid.org/0000-0002-7125-664X

Recebido em junbo de 2019

Aprovado em junho de 2019 